thereby ensuring adequate lumen diameter with no residual stenosis.

We applied this technique in 3 patients undergoing cardiopulmonary resuscitation who required life-saving extracorporeal membrane oxygenation support. Initiation of perfusion was rapid (14 \pm 3 minutes from incision to perfusion). Peripheral perfusion was easily detectable with vascular Doppler examination. In one case an inflow/outflow mismatch was suspected because the limb became slightly edematous after 12 hours of perfusion. In this case the prosthesis was not beveled, resulting in a noncommitted $90^{\circ}$ anastomosis. The potentially higher distal flow of this configuration in combination with the partially occluded femoral vein (through the venous cannula) could have contributed to this problem, which resolved after decannulation. The other patients did not have any perfusion-related complications (extracorporeal membrane oxygenation was discontinued after 74 and 54 hours, respectively).

\section{DISCUSSION}

Peripheral ischemia distal to the cannulation site is a severe complication of femoral arterial cannulation for extracorporeal life support. ${ }^{1,2}$ When the patient's hemodynamic condition is stable enough, suturing a beveled prosthetic graft to the artery and placing the distal end of the cannula at the level of the anastomosis avoids lumen occlusion by the cannula, thereby preventing any distal malperfusion. ${ }^{2}$ In dramatically critical situations rapid initiation of the lifesaving perfusion has first priority. With the described technique, perfusion can be initiated rapidly. Suturing of the side graft is slightly postponed and does not require any interruption of the perfusion. Beveling of the prosthesis allows for a more favorable flow direction toward the heart, potentially avoiding preferential distal flow.

There are also alternative techniques. ${ }^{3-5}$ Those with published clinical applications have in common the introduction of an additional catheter in the distal artery, which is then connected to the extracorporeal circuit. These techniques also allow for a rapid initiation of perfusion. However, the effective distal perfusion flow can be low because it is determined by the resistance of the connection of the perfusion catheter to the circuit and of the diameter of the catheter itself. In addition, after decannulation, the femoral arteries are left with 2 openings and potential thrombus formation between them, requiring careful vascular reconstruction.

In summary, we present a rapid femoral arterial cannulation technique for extracorporeal life support, which allows for unimpaired distal limb perfusion.

\section{References}

1. Gates JD, Bichell DP, Rizzo RJ, Couper GS, Donaldson MC. Thigh ischemia complicating femoral vessel cannulation for cardiopulmonary bypass. Ann Thorac Surg. 1996;61:730-3.

2. Vander Salm TJ. Prevention of lower extremity ischemia during cardiopulmonary bypass via femoral cannulation. Ann Thorac Surg. 1997;63:251-2.

3. Greason KL, Hemp JR, Maxwell JM, Fetter JE, Moreno-Cabral RJ. Prevention of distal limb ischemia during cardiopulmonary support via femoral cannulation. Ann Thorac Surg. 1995;60:209-10.

4. Madershahian N, Nagib R, Wippermann J, Strauch J, Wahlers T. A simple technique of distal limb perfusion during prolonged femoro-femoral cannulation. J Card Surg. 2006;21:168-9.

5. Magovern JA, Fonger JD, Wang DHJ, Kopilec D, Trumble DR, Smith DE. A femoral artery cannula that allows distal blood flow. J Thorac Cardiovasc Surg. 2005 130:684-6.

\title{
Absorbable pulmonary arterial banding: An optimal strategy for muscular or residual ventricular septal defects
}

\author{
Norihiko Oka, MD, PhD, Christian P. Brizard, MD, Matthew Liava'a, MBChB, and \\ Yves d'Udekem, MD, PhD, Melbourne, Australia
}

\footnotetext{
From the Department of Cardiac Surgery of the Royal Children's Hospital, the Department of Paediatrics of the University of Melbourne, and the Murdoch Children's Research Institute, Melbourne, Australia.

Disclosures: Authors have nothing to disclose with regard to commercial support.

Received for publication Dec 22, 2009; revisions received Feb 28, 2010; accepted for publication April 10, 2010; available ahead of print Sept 3, 2010.

Address for reprints: Yves d'Udekem, MD, PhD, Royal Children's Hospital, Flemington Rd, Parkville, Victoria 6009, Australia (E-mail: yves.dudekem@rch. org.au).

J Thorac Cardiovasc Surg 2011;141:1081-2

$0022-5223 / \$ 36.00$

Crown Copyright (C) 2011 Published by Elsevier Inc. on behalf of The American Association for Thoracic Surgery

doi:10.1016/j.jtcvs.2010.04.044
}

With conventional pulmonary arterial banding (PAB), a second surgical procedure to remove the band is compulsory, regardless of eventual ventricular septal defect (VSD) closure. Use of an absorbable PAB abolishes this requirement. ${ }^{1}$

In 2003, we started to use a custom absorbable PAB made of polydioxanone, mainly for patients in whom muscular and residual VSDs were expected to close spontaneously. Polydioxanone is a widely used biodegradable polymer that is known to keep $35 \%$ of its mechanical strength for about 3 weeks and to degrade completely in about 6 months. We hypothesized that a PAB made of this absorbable 
material would maintain an adequate pressure gradient long enough for the muscular or residual VSD to close spontaneously, and that the band would then degrade, allowing the pulmonary artery to grow and expand without the need for reintervention.

\section{MATERIALS AND METHODS}

Between 2003 and 2008, at the Royal Children's Hospital in Melbourne, Australia, 15 patients with a median age of 1.2 months (interquartile range, 0.4-2.8 months) underwent $16 \mathrm{PAB}$ procedures with absorbable polydioxanone bands. One patient required a reoperative $\mathrm{PAB}$ procedure before the successful spontaneous closure of his muscular VSD was observed. Of these 15 patients, 2 patients with single-ventricle physiology underwent $\mathrm{PAB}$ for short-term palliation, whereas the remaining 13 patients had residual VSDs or muscular VSDs expected to close spontaneously. Four of the 13 patients with VSDs had undergone a concomitant coarctation repair, and 2 had undergone repair of an atrioventricular septal defect. Indication for $\mathrm{PAB}$ was concomitant coarctation repair or residual immediate postoperative pulmonary to systemic perfusion ratio greater than 1.5 , as calculated from saturations of the blood collected in the right atrium and the pulmonary artery. Ten patients with VSDs who had follow-up longer than 1 year constitute the core of this study.

\section{Surgical Technique}

A 5-mm wide absorbable PAB was tailored from a polydioxanone tape (Johnson and Johnson, European Logistics Centre, Sint-Stevens-Woluwe, Belgium). These polydioxanone tapes are commercially marketed for joint surgery and are made of flat, woven, absorbable polydioxanone filaments. The custom PAB was then tightened and secured around the main pulmonary artery with nonabsorbable braided sutures until the distal systolic pressure fell below $50 \%$ of the aortic systolic pressure.

\section{RESULTS}

Median follow-up for the 10 patients who had been followed up for longer than 1 year was 40 months (interquartile range, 30.6-48.5 months). Immediately after surgery, 7 had an adequate gradient increase superior to $40 \mathrm{~mm} \mathrm{Hg}$. For these 7 patients, the median time after which a drop in the pressure gradient below $30 \mathrm{~mm} \mathrm{Hg}$ was observed was 7.9 months (interquartile range, 5-11 months; Figure 1). Three patients had low pressure gradients across the PAB $(18,23$, and $31 \mathrm{~mm} \mathrm{Hg})$. One patient, despite an initial gradient of $54 \mathrm{~mm} \mathrm{Hg}$, eventually required surgical VSD closure 6 months after PAB. None of the remaining 9 patients required additional surgical or catheter VSD closure. At the last echocardiographic follow-up, after a median of 14.4 months (interquartile range, 12-22 months), there were no more pulmonary obstructions at the level of the PAB and no significant residual VSDs. The mean pulmonary arterial gradient was $4.7 \pm 5.1 \mathrm{~mm} \mathrm{Hg}$. The narrowing was no longer reported.

\section{DISCUSSION}

In 1991 and 1992, the first few clinical trials of absorbable PABs were reported. ${ }^{2,3}$ Bonnet and colleagues ${ }^{4}$ described a series of patients who underwent surgical

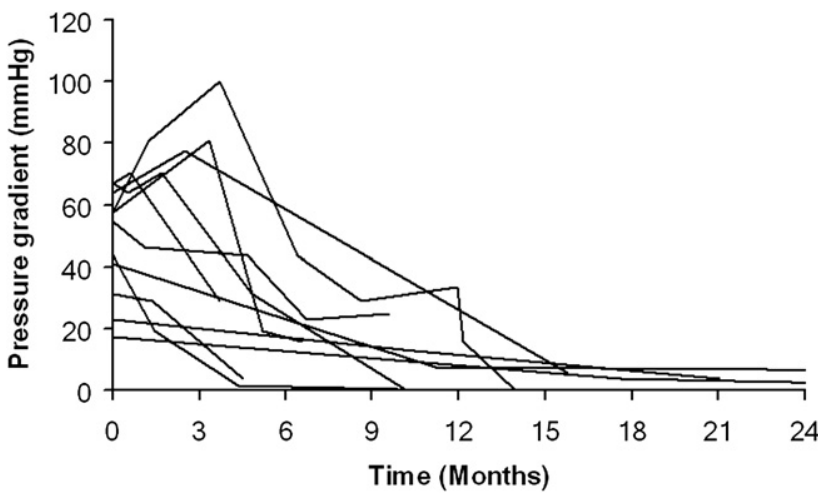

FIGURE 1. Evolution of pulmonary arterial gradient after pulmonary arterial banding with an absorbable polydioxanone band.

treatment of aortic coarctation with VSD by placement of an absorbable PAB. They were able to avoid subsequent cardiac surgery in $91 \%$ of cases. We recently reported the usefulness of this adjunct technique after surgical repair of complex multiple VSDs. ${ }^{5}$ Our study confirms that PAB with an absorbable polydioxanone band is a useful strategy for VSDs that are expected to close. Once the absorbable band starts to lose its strength, presumably around 6 postoperative months, the main pulmonary artery is free to expand and grow. Because we do not schedule follow-up echocardiography more often than every 3 months, it is difficult to know exactly when the band loses its function. It seems, however, that the absorbable band eventually dissolves and does not leave any stenosis. In our series, the time necessary to achieve dissolution of the band was sufficient to allow spontaneous VSD closure in all but 1 case. Nine of 10 patients avoided reoperation for band removal.

In conclusion, $\mathrm{PAB}$ with an absorbable polydioxanone band is often a successful strategy for patients with muscular or residual VSDs that are expected to close spontaneously, because it avoids the need for a second reoperation to remove the band.

\section{References}

1. Muller WH Jr, Danimann JE Jr. The treatment of certain congenital malformations of the heart by creation of pulmonary stenosis to reduce pulmonary hypertension and excessive pulmonary blood flow: a preliminary report. Surg Gynecol Obstet. 1952;95:213-9.

2. Vince DJ, Culham JA, Le Blanc JG. Human clinical trials of the dilatable pulmonary artery banding prosthesis. Can J Cardiol. 1991;7:319-42.

3. Gutiérrez de Loma J, Ferreiros Mur M, Castilla Moreno M, García Peña R, González de Vega N. [Reabsorbable banding. Our initial experience]. Rev Esp Cardiol. 1991;44:677-9. Spanish.

4. Bonnet D, Patkaï J, Tamisier D, Kachaner J, Vouhé P, Sidi D. A new strategy for the surgical treatment of aortic coarctation associated with ventricular septal defect in infants using an absorbable pulmonary artery band. J Am Coll Cardiol. 1999;34:866-70.

5. Brizard CP, Olsson C, Wilkinson JL. New approach to multiple ventricular septal defect closure with intraoperative echocardiography and double patches sandwiching the septum. J Thorac Cardiovasc Surg. 2004;128:684-92. 